Revista Aspas

ppgac - USP

Do lado de fora do teatro

\title{
A FORMAÇÃO DE DIRETORES DE ARTE NO BRASIL
}

\author{
THE FORMATION OF PRODUCTION DESIGNERS IN BRAZIL
}

\section{LA FORMACIÓN DE DIRECTORES DE ARTE EN BRASIL}

\section{Carolina Bassi de Moura}

Carolina Bassi de Moura

Doutora e Mestre em Artes Cênicas pela ECA/USP, graduada em Comunicação Social - Rádio e TV pela UNESP. Pesquisadora, professora adjunta e coordenadora do Bacharelado em Cenografia e Indumentária da UNIRIO. Diretora de arte, cenógrafa e

figurinista. Interessada na construção poética da imagem em cinema, TV, teatro, performance, fotografia, literatura, música e artes em geral. 


\section{Resumo}

A formação em direção de arte no Brasil, atualmente, é tortuosa, intuitiva e fragmentada, dificultando o aprendizado do estudante, o trabalho do profissional no mercado de trabalho e podendo prejudicar a qualidade das produções. Este artigo faz um cruzamento de minha observação como profissional em produções cinematográficas e docente pesquisadora em universidades com a de outros profissionais da área acerca do tema. Serão usadas a minha tese $A$ direção e a direção de arte, (MOURA, 2015), publicações (BRUTUCE; BOUILLET, 2017) (HAMBURGER, 2014) e debates específicos (SEMANA ABC, 2015 e 2018). Desejo com este artigo apontar necessidades desta formação, para que um pensamento possa ser melhor desenvolvido nas universidades, suprindo as carências apontadas.

Palavras-chave: Direção de arte; diretor(a) de arte; formação superior; cinema;dramaturgia visual.

\section{Abstract}

Currently, training in art direction in Brazil is tortuous, intuitive and fragmented, making it difficult for the student to learn, for the professional to work in the job market, and to affect the quality of the productions. This article crosses my observation as a professional in cinematographic productions and as a research professor at universities and technical schools, with that of other professionals in the field on the subject. My thesis The direction and production design, (MOURA, 2015), publications (BRUTUCE; BOUILLET, 2017) (HAMBURGER, 2014) and specific debates (SEMANA ABC, 2015 and 2018) will be used. With this article I would like to point out the needs of this formation, so that a thought can be developed in the universities, supplying the deficiencies.

Keywords: Production Design; Production Designer; high school; cinema; visual dramaturgy.

\section{Resumen}

Actualmente, la formación en Production Design en Brasil es tortuosa, intuitiva y fragmentada, lo que dificulta que el estudiante aprenda, que el profesional trabaje en el mercado laboral y que afecte la calidad de las producciones. Este artículo cruza mi observación como profesional en producciones cinematográficas y como profesora investigadora en universidades y escuelas técnicas, con la de otros profesionales en el 
campo en la materia. Se utilizará mi tesis La dirección y production design, (MOURA, 2015), publicaciones (BRUTUCE; BOUILLET, 2017) (HAMBURGER, 2014) y debates específicos (SEMANA ABC, 2015 y 2018). Con este artículo deseo señalar las necesidades de esta formación, para que se pueda desarrollar un pensamiento en las universidades, supliendo las necesidades.

Palabras claves: Production Design; Production Designer, formación superior; cine; dramaturgia visual

O termo "direção de arte", como traduzido no Brasil, desde o seu surgimento no início do século $X X$, vem adentrando muitos espaços $\mathrm{e}$ despertando a atenção para este profissional. Hoje, estamos acostumados a vê-lo figurar também entre os profissionais das séries e minisséries televisivas, a vê-lo aparecer em fichas técnicas de espetáculos teatrais e de shows musicais, além de sabê-lo uma figura importante na realização de campanhas publicitárias audiovisuais e impressas. Considerando que estes campos criativos guardam semelhanças entre si, mas também muitas especificidades, faz-se a pergunta: em todos eles, o diretor de arte desempenha o mesmo papel? O que esperar, exatamente, de sua atuação num mercado de trabalho tão vasto? E, para tanto - como se dá a formação de um diretor de arte?

Uma informação crucial para o entendimento desta função é o fato de que o diretor de arte surgiu no cinema como um desmembramento da função do diretor. Foi na Hollywood do final da década de 1930, período em que os produtores tinham supremacia sobre o filme, que ele surgiu com o nome de production designer. Aprimorou a função do art director ${ }^{1}$, que desenhava os cenários, passando a desenhar as cenas - ou seja, os cenários e os personagens em enquadramentos específicos, tudo sob uma

\footnotetext{
' De onde se entende a tradução da terminologia feita no Brasil, para designar a função. "Diretor de arte" parece mais claro do que se usássemos a tradução literal "designer/desenhista de produção". O uso da palavra "arte" revela uma função reservada a alguém que tenha propriedade sobre o caráter artístico de uma obra a ponto de "dirigir" toda uma equipe sobre esse aspecto. Ao expormos isto, revelamos a proximidade entre este profissional e a direção, o que pode se dar de modo muito produtivo, mas também despertar alguns conflitos. Antecedendo o termo art director, até a década de 1920, era utilizado technical director. A insistência no uso da palavra "diretor", gerou reivindicação por parte dos diretores enciumados em relação ao seu lugar de ação.
} 
iluminação e intenções dramáticas imaginadas em conjunto com a direção de fotografia e a direção. Dessa forma, o grande ganho da nova função foi compreender o valor dramático da imagem fílmica e assumir um papel fundamental na construção desse valor. ${ }^{2}$

Na mesma década, no Brasil, acontecia a instalação dos grandes estúdios, sinalizando o desejo de seguir a escola americana e, provavelmente, de contar com o mesmo tipo de profissionais. Mas, no início, as fichas técnicas dos filmes nacionais contavam com créditos para "cenário e figurinos", e não para "direção de arte". O primeiro crédito foi concedido só em 1985, a Clóvis Bueno, como diretor de arte em O beijo da mulher aranha, de Hector Babenco.

Segundo a pesquisadora Débora Brutuce, "o termo cenografia era utilizado para designar [...] o que entendemos atualmente como a função da direção de arte", resguardando as devidas proporções na comparação (BRUTUCE; BOUILLET, 2017, p.13) Ela observa a equivalência entre os termos num período inicial, pois haviam "cenógrafos-figurinistas" conferindo unidade para as duas áreas e estabelecendo linguagem visual coerente, como Clóvis Bueno. ${ }^{3}$ Mas, ao salvaguardar "as devidas proporções", imaginamos que alguns conhecimentos, bem como alguns procedimentos de trabalho, não passassem pelos "cenógrafos-figurinistas". Tais profissionais tinham construído uma trajetória anterior no teatro ${ }^{4}$ traziam seus conhecimentos daquela linguagem. Tinham uma bagagem específica, agregavam seus saberes ao projeto e aprendiam outros, na prática.

Se, no passado, alguns cenógrafos de teatro haviam migrado para o cinema, e foram formalizando a sua especialidade na linguagem audiovisual, hoje, outros cenógrafos têm querido assinar como diretores de arte - só que no teatro. Percebo uma incongruência nisto, pois o diretor de arte surge no cinema, e não no teatro, justamente para atender à lógica de funcionamento industrial que tende a imperar nas produções cinematográficas. Uma lógica

\footnotetext{
${ }^{2} \mathrm{O}$ production designer deve demonstrar esta compreensão em seus procedimentos de trabalho, desde a concepção até a orquestração de sua volumosa equipe, no arranjo cuidadoso dos diversos recursos plásticos, componentes de sua linguagem.

${ }^{3}$ E também Luiz Carlos Ripper, Anísio Medeiros e Régis Monteiro, conforme lembrou a diretora de arte Vera Hamburger em entrevista à mesma publicação (idem. p.165).

${ }^{4}$ No caso de Clóvis Bueno, inclusive, uma passagem como ator e cenógrafo.
} 
que acontece devido aos grandes orçamentos e às equipes numerosas que Ihes são características e necessárias para que tudo se cumpra no menor tempo possível, e que, normalmente, não costuma fazer parte do teatro. É preciso o diretor de arte no cinema para dar unidade ao trabalho desenvolvido por muitas mãos e para estabelecer uma importante "ponte comunicacional" entre o diretor e essa equipe. No teatro, o/a cenógrafo/a e o/a figurinista devem se comunicar entre si (caso não sejam a mesma pessoa) e diretamente com o diretor, sem necessitar de intermediários, pois as equipes são muito menores, em geral ${ }^{5}$.

As qualidades evocadas pela nomenclatura em questão - arte e direção - parecem conferir uma "aura de poder a mais" para o profissional. No entanto, além da referida "aura de poder", o diretor de arte possui maior responsabilidade sobre o todo do trabalho desenvolvido, desempenhando um papel diferente daquele do cenógrafo de cinema. E, ao lidar com mais aspectos dentro da obra fílmica, o cachê do diretor de arte é proporcionalmente maior do que o de um cenógrafo.

Sobre as nomenclaturas, a diretora de arte e cenógrafa Lia Renha comentou:

Agora os produtores de cenografia mudaram o nome também, que nem os produtores de objeto fizeram [estes são chamados produtores de arte na TV]. Todo mundo passa para a palavra arte. [...] Fica impossível de compreender!

Produção de cenografia agora virou coordenação de arte. [...] "Coordenador" parece que é chefe até do diretor de arte, dos cenógrafos... [...] Resultado: virou um caos porque agora tem problema de poder.

[...] Todo mundo está sem formação pra aquilo... É uma bagunça danada e pra fazer o trabalho está ficando difícil, desgastante, porque virou um carreirismo! (MOURA, 2015, p. 465)

Escolher nomes diferentes para profissionais que desempenham a mesma função, ou ainda, manter o mesmo nome para profissionais que atuam em áreas diferentes e que não tiveram uma preparação específica para cada uma delas, tende a gerar confusões. Isto reflete problemas vindos da formação e causa novos ruídos, pois muitos absorvem seus

\footnotetext{
${ }^{5}$ Talvez, no caso de espetáculos musicais, por exemplo, que costumam ser grandiosos, isto seja proveitoso.
} 
conhecimentos na prática. Por isso, Lia Renha se ressente daqueles que migram para a área sem o devido preparo e, sobre eles, comenta:

\begin{abstract}
A pessoa não sabe nem que [cenografia] é um curso superior! E aí não sabe o que não sabe! Não tem ideia! [...] a cenografia todo mundo "deleta", porque pensa, "cenografia precisa desenhar, projetar e daí é melhor direção de arte". Eu quero ser diretor de arte! Parece que é mais fácil. Todo mundo quer ser diretor de arte, aí faz um curso... [...] Porque tem cursos no mundo inteiro para quem já é, inclusive, diretor de arte, ou cenógrafo. Se já tem prática, faz um curso [rápido] e agrega. Mas [...] Como é que uma pessoa vai ter uma formação de arquitetura ou de cenografia nesse tempo? Arquitetura são 5 anos de estudo no mínimo! (MOURA, 2015, p.463)
\end{abstract}

Cursos livres como estes têm muita procura. São ministrados no Brasil e em outros países, mas, devido à sua curta duração, não se pode considerar que, apenas eles, possam vir a formar, adequadamente, diretores de arte.

O aprendizado informal de profissionais da direção de arte também acarreta dificuldades no enfrentamento do mercado de trabalho. O nãodelineamento claro da função e de todo o universo que ela compreende, resulta indiretamente no desconhecimento das competências do cargo por parte dos outros profissionais da equipe que, desse modo, podem confundir a quem devem fazer determinadas solicitações, atrapalhando o andamento do todo. O diretor de arte, Tulé Peake sinalizou: "Até hoje, em muitos trabalhos, eu sinto que o próprio diretor e a produção não sabem muito bem como lidar com a gente, não sabem muito bem pra quê que a gente serve. Não sabem muito bem o que pedir, o que esperar de um diretor de arte." (SEMANA ABC, 2015)

Um exemplo desses confrontos com a equipe acontece com relação às questões de enquadramento, que devem ser decididas em conjunto diretor, diretor de arte e diretor de fotografia. Mas, nas equipes brasileiras de cinema, é comum que às vezes negligenciem a participação dos diretores de arte. Ao desenvolver um filme com profissionais nacionais e internacionais (Nosso Lar, 2010, de Wagner de Assis), Lia Renha vivenciou o problema e o primeiro a se queixar foi o diretor de fotografia suíço, Ueli Stieger. Ela comentou o fato: "Está errado, a equipe está falando com ele coisa que tem 
que falar comigo! Então, no Brasil, está ficando uma confusão tão grande que até o cinema que tem a equipe feita, já está sofrendo essa confusão da televisão, em que não existe direção de arte."(MOURA, 2015, p. 466)

As inter-relações da direção de arte e da direção de fotografia são um conhecimento geralmente pouco vinculado à direção de arte pelas nossas escolas. Mas há um cuidado necessário na escolha das locações, que passa por questões da fotografia, incluindo iluminação, câmeras e lentes:

Direção de arte não é "colocar florzinha", pintar e ficar bonitinha a locação. [...] Quando você olha uma locação, você tem que ver através da lente para responder por ela. Tem umas que são esquisitas, tem vezes que o diretor fala, "não sei porque a Lia está escolhendo isso". Eu estou vendo como ela vai ficar, ela tem potencial! A gente vai interferir, tem que interferir. É muito raro uma locação assim, tão pronta... Você tem que virá-la para aquela história, para as lentes. (idem)

A colocação de Lia deixa clara a necessidade de que o diretor de arte tenha também essas competências técnicas.

Na telenovela não há um diretor de arte como no cinema ${ }^{6}$, como foi dito, e portanto, não há quem faça a amarração conceitual com os figurinistas, caracterizadores e cenógrafos, se o diretor mesmo não o fizer. Como essas não são funções autônomas dentro do todo, se não forem costuradas, não haverá uma ideia exposta e, logo, nenhuma estética. Sobre esta situação, Lia Renha expôs o constrangimento pelo qual profissionais televisivos já passaram devido à falta de coerência de seu trabalho com o todo, na ausência de uma amarração de conceito, o que, não raro, resultou em demissões.

Outro conhecimento necessário é o que diz respeito ao bom aproveitamento do orçamento, um pensamento de produção. Segundo a escola americana de cinema, este raciocínio está embutido na função de production design, com o que Lia Renha concorda:

Totalmente. E está incluído na função. Por exemplo, eu leio um texto. [...] Primeira coisa, eu tenho que ver a quantidade de [cenas] externas com a quantidade de [cenas] de estúdio. Preciso saber o tempo das cenas, porque eu vou falar: olha, essa cena

\footnotetext{
${ }^{6}$ Diretor de arte na televisão não tem, em nenhuma delas [emissoras]. Só tinha eu fazendo isso. [...] (MOURA, 2015, p. 465)
} 
aqui não é estúdio, é locação. "Ah, por quê?". Porque o tempo dela é tal, ela só tem uma vez... Ou então, leio tudo, aí eu vejo que tem um apartamento que está com uma cena no quarto, outra no banheiro e outra na cozinha. Eu vou ler direitinho. Faço a minha decupagem, chego e proponho ao diretor: Vamos tirar essa cozinha? Porque tem cenas em que a cozinha é mais importante, mas, no caso, aqui, não era. Então, esse diálogo pode ser feito na sala. Porque cozinha é área molhada e custa uma fortuna. $E$ teria sido gasto à toa. Mas, "dramaticamente" você tem que saber. Você tem que saber se "dramaticamente" não está alterando, senão você não vai propor isso. (MOURA, 2015, p. 467)

Ao mencionar a habilidade com a produção dos cenários, Lia revela outra habilidade muito importante da direção de arte, que é o conhecimento sobre o texto. Ela enfatiza a importância de ter estudado muito, desde pequena, interpretação de texto, para o bom desempenho da sua profissão.

Nesse sentido, é necessário, finalmente, comentar sobre a dificuldade de entendimento de texto que muitos têm no Brasil, que perpassa tanto a interpretação do texto verbal quanto do texto imagético e audiovisual. A soma aleatória de palavras num discurso resulta tão sem sentido, quanto um agrupamento de objetos, formas e cores de forma impensada em um cenário, escolhidos sem a compreensão exata do que tais elementos juntos significam.

Isto é uma reflexão seríssima a meu ver, pois o problema acontece nas escolas superiores de modo geral. Em minhas atividades, como docente de graduação e pós-graduação, sempre que são dados textos literários aos alunos para que eles desenvolvam uma dramaturgia visual, há muita dificuldade de interpretação. Os alunos, em geral, não compreendem bem o significado dos textos. E, muito pior, costumam não perceber que possuem esse déficit de leitura. É preciso provocar muito o entendimento, para uma compreensão mais a fundo.

O problema é de linguagem - e é da ordem da leitura e da construção. Não conseguem ler, como não conseguem se expressar. Não conseguem compreender o sentido construído nos textos literários para, então, propor uma transcriação visual para aquelas ideias. E, também, têm dificuldade de articular as ferramentas plástico-visuais para expressar um pensamento. 
Lia Renha defende que se tenha uma formação superior para trabalhar como diretor de arte e sugere o curso de Cenografia. Mas há apenas duas graduações em Cenografia e Indumentária no Brasil, ambas situadas no Rio de Janeiro. A UFRJ possui duas habilitações separadas cenografia e figurino. A UNIRIO oferece formação integrada, que me parece mais interessante para quem tenha interesse em vir a ser um diretor de arte. O curso tem disciplinas específicas, mas também integradas, incluindo o exercício da montagem de espetáculos em diferentes momentos do currículo. No entanto, o curso não costuma oferecer, entre as disciplinas obrigatórias, conhecimentos mais específicos da linguagem audiovisual, voltados à fotografia, por exemplo, ou ao funcionamento das equipes, o que seria um grande ganho para os que quisessem ingressar na área.

O diretor de arte e cenógrafo, Mário Monteiro teve uma formação mista, cursou Arquitetura e admite que embora o arquiteto trabalhe melhor questões técnicas do espaço, ele é "meio duro". Ele considerou efetivo mesmo o extinto Liceu de Artes e Ofícios, uma espécie de escola de Desenho Industrial da época, "voltada um pouco para a Cenografia, porque tinha até cenógrafos que eram professores da escola" com aulas de cenografia, desenho de mobiliário, estilos de arte decorativa, entre outras. (MOURA, 2015, p.461)

O cenógrafo e diretor de arte, João Irênio, nos dá a dica sobre passar por todas as funções do departamento de arte para entender cada uma delas. Ele teve, além da formação em Arquitetura, um aprendizado muito particular:

O meu pai [Irênio Maia] era cenógrafo, diretor de arte e figurinista. [...] Com 15 ou 16 anos, a gente começou a trabalhar junto, ele me formou nos vários segmentos da cenografia. Eu trabalhei até como ajudante de carpintaria, e dali, como carpinteiro, eu fui aprendendo a recortar, a montar, a pregar, a como fazer e como calcular uma estrutura. Depois da carpintaria, eu passei para a pintura - "pintura lisa" e "pintura de arte" - escultura, e as coisas começaram a se incrementar um pouco. Aí, por fim, eu fui fazer produção cenográfica, que é o momento em que você dá todo o suporte pra toda a equipe poder executar aquele trabalho. Ele, na verdade, foi me "costurando" por trás da cenografia, me dando todas as ferramentas para que no futuro eu pudesse me concentrar no que realmente a gente está discutindo aqui, que é o segmento do cenógrafo, do diretor de arte, quanto à elaboração 
do personagem. É basicamente, toda essa bagagem que eu acho que você precisa ter de qualquer forma. Você precisa ser um bom artesão. Você precisa [...] conhecer os materiais. (MOURA, 2015, pp.461-462)

Sobre o conhecimento de programas digitais de planejamento técnico de cenografia, todos os entrevistados em minha tese foram unânimes em dizer que são importantes para agilizar o trabalho. Mas, fizeram questão de dizer também, que não "aposentaram" completamente os trabalhos manuais como o desenho à mão e a maquete física. "Você misturar o arcaico com a tecnologia de ponta, isso eu acho que é muito interessante. Eu acredito que, inclusive, a cenografia, ela sempre será arcaica." (idem, p. 462)

O diretor de arte Marcos Pedroso, graduou-se em Artes Plásticas, depois passou pelo teatro (ainda na faculdade), e, por último, pelo cinema. Ele relatou que foi necessário buscar aprimoramento enquanto já estava trabalhando na área:

\begin{abstract}
A demanda dos filmes que eu fiz, era a de que eu ajudasse o diretor num processo de construção do personagem. [...] Eu não tinha essa formação. Eu não sabia nada de figurino, eu tinha uma formação geral, plástica... Não sabia de maquiagem. Vagarosamente você vai somando dados. [...] Hoje tem os efeitos, que você tem que "dar pitaco", e pós [produção]. Nos últimos três filmes, eu sentei [com o montador] na pós produção pra fazer marcação de luz, porque hoje em dia você muda o cenário, muda a cor... Cada vez esse guarda-chuva vai acolhendo mais coisas. (SEMANA ABC, 2015)
\end{abstract}

Sobre a formação do diretor de arte, Vera Hamburger também observou que geralmente tem se dado mais nos campos de arquitetura, design e artes plásticas, e raramente no audiovisual. Concorda que há diretores de arte inteiramente autodidatas e sinaliza que é na prática onde mais se tem aprendido as particularidades da linguagem. (HAMBURGER, 2014. p.53)

Nas graduações em Cinema e Audiovisual no Brasil, a formação em Direção de Arte, em geral, tem sido rasa. O que vemos é que ou não há a disciplina de Direção de Arte nas grades curriculares destes cursos; ou ela consta, mas é opcional, o que pode dar aos alunos a falsa impressão de ser menos importante e necessária do que as outras; ou ainda, que, mesmo os que têm interesse em formar-se com outras habilitações, não precisam 
adquirir os conhecimentos referentes a esta competência. Em outros casos, a disciplina de Direção de Arte está entre as matérias obrigatórias e, aos poucos, conquista uma carga horária mais igualitária ao longo dos anos. Segundo o diretor e roteirista Ninho Moraes, "Falta espaço para a direção de arte nos cursos universitários, que em média, ocupam $1,5 \%$ da grade, e a maioria dos alunos não percebe a importância da direção de arte para a formação e para o cinema." (SEMANA ABC, 2015)

A tese $O$ cinema digital e seus impactos na formação em cinema e audiovisual (SILVA, 2012, pp.236-280), que parece não considerar obrigatório o campo da direção de arte nessa formação ${ }^{7}$, parte, dentre outros dados, de um mapeamento de currículos universitários em Cinema e Audiovisual. 26 de 52 currículos listados possuem 1 semestre obrigatório de Direção de Arte, mas, importantes graduações como a da USP e da UFSCar não oferecem essa disciplina obrigatória. Poucas oferecem períodos avançados dessa linguagem, e variações abrangendo cenografia e figurino, ou conhecimentos em áreas específicas como Direção de Arte em Mídias, Direção de Arte em Animação e Direção de Arte em TV, como a do SENAC, que parece ser a mais completa neste sentido.

Buscando entender estas discrepâncias, penso que a reflexão, até o momento, sobre a natureza do ofício da direção de arte, tenha sido insuficiente.

Primeiro, não se trata de uma competência estritamente técnica e operacional. Ainda que trabalhe com conhecimentos técnicos variados ${ }^{8}$, para desenvolver as etapas técnicas é preciso conceber antes o que será realizado. É preciso criar uma dramaturgia visual, o que para uma obra fílmica, audiovisual, exige conceito e é fundamental. Como toda atividade

\footnotetext{
${ }^{7}$ A tese é admirável nos apontamentos que faz e na análise dos dados pesquisados, mas não questiona a ausência do estudo da direção de arte naqueles cursos, nem considera os impactos do cinema digital para o desenvolvimento do seu trabalho especificamente. Expõe, por exemplo, no capítulo: 4. Cinema digital - os novos desafios e suas influências no ensino de Cinema e Audiovisual: 4.1. Ensino teórico; 4.2. Dramaturgia Audiovisual; 4.3. Produção; 4.4. Fotografia e Direção; 4.5. Som; 4.6. Edição e a Finalização; 4.7. Circulação - Distribuição e Exibição e 4.8. Preservação. Menciona a direção de arte em poucos momentos, como uma área específica e técnica, e inexplicavelmente não dá a ela a mesma ênfase dada à direção de fotografia, à montagem ou ao som. Mesmo dentro de "dramaturgia audiovisual", não consta um pensamento sobre a direção de arte.

${ }^{8}$ Conhecimentos técnicos de desenho de cenário, cenotécnica, desenho de personagem, técnicas de maquiagem, modelagem de figurino, etc.
} 
artística, a direção de arte, o roteiro, a direção, o som, a edição/montagem, são áreas que empreendem esforços técnicos e intelectuais na sua execução, que merecem e precisam ter seu pensamento formalizado dentro do curso superior destinado à linguagem em que serão trabalhadas.

Segundo, ainda se esta competência for considerada do diretor, ele precisaria estudá-la em sua formação.

E aí entra outra questão importante, a diferenciação ideológica entre esses cursos: alguns voltados para um "cinema de autor" e outros para atender ao "mercado". Aqueles voltados para a autoria, tendem a desconsiderar a direção de arte, enquanto aqueles voltados para o mercado, não. Mesmo sabendo que o debate acerca da autoria no cinema é extenso, pensemos nesta questão. Seria possível um "cinema de autor" displicente com sua linguagem plástica? Dito isso, por que não formalizar, nesses currículos, um pensamento sobre a elaboração estética da obra fílmica/audiovisual e também os parâmetros técnicos para tal, em disciplinas de direção de arte?

No princípio, a formação dos profissionais de cinema no Brasil era feita em cursos livres. (SILVA, 2012, p.164) Com a intenção de fomentar a linguagem do cinema e preparar intelectualmente seus autores para elaborarem suas criações, os primeiros cursos superiores em Cinema foram criados na década de 1960. Priorizaram a formação de diretores sob forte influência da lógica do "cinema de autor", presente no Cinema Novo. O movimento, inspirado no neorrealismo italiano e comprometido com a luta de classes, buscava a construção de uma imagem sem artifícios. Esta política do "cinema de autor" faz uma forte oposição àquela dos grandes estúdios, mais afeita à escola hollywoodiana, que prezava a visão do produtor. E é nela, justamente, em que surge o production designer, cuidando da visualidade para o autor, ou em conjunto com ele. Teria, então, ficado marcada a atuação do diretor de arte em prol de uma visão de mercado, contrariando a lógica do "cinema de autor", .

Ao rever a noção de autoria no cinema do século XXI, o diretor, professor e pesquisador, Carlos Gerbase expõe o acúmulo de funções como "condição sine qua non para que o diretor seja considerado um autor". 
(SILVA, 2012, p. 164) Seu estudo enfocou filmes de baixíssimo orçamento 9 , mas isto quer dizer, então, que a autoria estaria restrita apenas a este nicho? Que dizer de obras como as de Luiz Fernando Carvalho ou Guel Arraes, cuja visualidade é impactante, tanto para as construções de sentido poético, como para a constituição desses diretores enquanto autores? Carvalho, que costuma acumular a função de diretor e diretor de arte, em Hoje é dia de Maria (2005), depois de já ter iniciado a construção de cenário em estúdio, percebeu que a estética não atendia a ideia essencial do trabalho. Foi preciso convidar Lia Renha para que empreendesse sua visão de diretora de arte e ajudasse a pensar a questão, conforme ambos relataram em entrevista à minha tese. Todo o trabalho desenvolvido até então precisou ser desconsiderado. Construíram um domo porque ficou claro que o problema era o de que "as buscas humanas", tema central da minissérie, sendo infinitas, não poderiam estar encerradas num espaço com quinas, arestas... não se podia ver o seu fim. Tratava-se então de uma questão técnica, mas não só. Tratava-se de uma metáfora visual.

\section{Considerações finais}

Expostas todas estas questões, me parece despropositada a justificativa para a não sistematização do pensamento e da construção da linguagem plástica em disciplinas de direção de arte nas matrizes curriculares em Cinema e Audiovisual. A plasticidade de uma obra é extremamente importante para a construção da autoria, assim como das metáforas visuais, que tanto podem caracterizar o trabalho de um autor.

A sistematização da linguagem da direção de arte, que abrange um campo tão vasto de conhecimentos, deveria expor com suficiente clareza o seu léxico, o seu funcionamento, bem como as competências de todos os artistas que a tornam dinâmica. Deveria unir os saberes espalhados em diversos currículos superiores, como apontado, em vez de obrigar o futuro profissional a buscar por eles sozinho, de forma fragmentada e incerta. São

\footnotetext{
${ }^{9}$ No Brasil e na França (2004-2009).
} 
conhecimentos tecnológicos e artesanais, técnicos e conceituais, e ainda, todas as outras matérias teóricas de construção de linguagem e formação de repertório, extremamente importantes para a formação deste artista.

Acredito que com este artigo, tenha sido possível entender necessidades da função que não estão sendo atendidas no mercado de trabalho e, a partir delas, seja possível projetar, na formação superior, meios de atendê-las. Foram muito úteis os relatos dos profissionais da área, no que diz respeito aos saberes e experiências considerados importantes em seus processos de formação. Afinal, se nenhum dos currículos superiores apontados têm sido suficientes para dar conta da formação do diretor de arte, porque não pensar em como reunir todos os pontos fortes destacados em um único curso?

Seria uma nova graduação? Uma habilitação de um dos cursos superiores: Cinema e Audiovisual, ou Cenografia? Ou um curso de pósgraduação strictu sensu profissionalizante?

Questões ainda pairam sem resposta. Será preciso o empenho de muitos em debater o tema para empreender um caminho nas universidades e alterar a situação estabelecida.

\section{REFERÊNCIAS}

BRUTUCE, Débora; BOUILLET, Rodrigo. A direção de arte no cinema brasileiro. Rio de Janeiro: Caixa Cultural, 2017.

HAMBURGER, Vera. Arte em cena. São Paulo: Edições Sesc, 2014.

MARQUES, Aída; RODRIGUES, Luciana. CADERNOS DO FORCINE - Fórum de Ensino de Cinema e Audiovisual. vol. 1, 2014.

AUTOR. A direção e a direção de arte - construções poéticas da imagem em Luiz Fernando Carvalho. Tese de Doutorado. São Paulo: ECA/USP, 2015.

SEMANA ABC. Formação do diretor de arte foi tema da Semana ABC. Mediação: Cassio Amarante. Ciro Pirondi, Marcos Pedroso, Ninho Moraes, Tulé Peake. 2015 Disponível em: https://www.youtube.com/watch?v=mpRMB0p3z8\&list=PLFV9hlpiXWyTwLfLk9wOMa0FB8xa8Er0g. Acesso em 12 mai 2021. 
A formação de diretores de arte no Brasil

SEMANA ABC. Direção de arte: a concretização da expectativa a partir da realidade. Mediação: Marguerita Pennacchi. Carolina Bassi de Moura, Chiquinho Andrade, Marcos Pedroso e Vera Hamburger, 2018. Disponível em:

https://www.youtube.com/watch?v=qTPWc8OJjgA Acesso em 12 mai 2021. SILVA, Luciana Rodrigues. O cinema digital e seus impactos na formação em cinema e Audiovisual. Tese de Doutorado. São Paulo: ECA/USP. 2012. 